\title{
Modeling the Burden of Abdominal Aortic Aneurysm in the USA in 2013
}

\author{
Mark Stuntz \\ Deerfield Institute, New York, N.Y., USA
}

\section{Key Words}

Epidemiology · Cardiovascular disease - Mortality · Survival . Aneurysm $\cdot$ Aortic dissection $\cdot$ Women

\begin{abstract}
Objectives: Abdominal aortic aneurysm (AAA) is a pathological condition characterized by an abnormal, localized dilatation of the lower part of the aorta. Due to a lack of data on the natural history of AAA and risk of death from other cardiovascular diseases attributable to $A A A$, the true number of AAA-attributable deaths may be higher than currently estimated. This study aims to produce more realistic estimates of the burden of AAA. Methods: A disease-modeling software, DisMod II, was used to assess the AAA burden via a multistate life table. Inputs included population, all-cause mortality, size- and sex-specific AAA prevalence, and relative risk of death estimates for persons with AAA compared with persons without AAA. Results: There were 2,347,339 prevalent cases of AAA in the USA in 2013 (95\% Cl: 2,131,964$2,524,116)$, resulting in 41,371 deaths attributable to AAA (95\% Cl: 34,090-49,234). Females constituted $21.1 \%$ of prevalent cases and $45.2 \%$ of deaths, compared with males constituting $78.9 \%$ of prevalent cases and $54.8 \%$ of deaths. Conclusions: This work shows that the burden of mortality at-
\end{abstract}

\begin{tabular}{ll}
\hline KARGER & @ 2016 The Author(s) Karger \\
& Published by S. Karger AG, Basel Open cicess \\
& $0008-6312 / 16 / 1352-0127 \$ 39.50 / 0$ \\
E-Mail karger@karger.com & This article is licensed under the Creative Commons Attribution- \\
www.karger.com/crd & NonCommercial-NoDerivatives 4.0 International License (CC BY- \\
& NC-ND) (http://www.karger.com/Services/OpenAccessLicense). \\
& Usage and distribution for commercial purposes as well as any dis- \\
tribution of modified material requires written permission.
\end{tabular}

tributable to AAA is more than twice the current estimates from the American Heart Association. Females account for a disproportionately high percentage of deaths despite constituting a low percentage of prevalent cases.

(c) 2016 The Author(s)

Published by S. Karger AG, Basel

\section{Introduction}

Abdominal aortic aneurysm (AAA) is a pathological condition characterized by an abnormal, localized dilatation of the lower part of the aorta [1]. The general consensus for defining an AAA is aortic diameter $\geq 1.5$ times the normal diameter at the level of the renal arteries, which typically equates to a minimum diameter of $3.0 \mathrm{~cm}$ to be considered an AAA [2]. The prevalence of AAA has previously been shown to be approximately $4-5 \%$ among adults over 50 years of age, although it is several times more common in men than in women [3-5].

The United States Preventive Services Task Force (USPSTF) currently recommends one-time screening for AAA in men aged 65-75 years who have ever smoked and recommends that clinicians selectively offer screening for AAA in men who have never smoked. However, the USPSTF concludes that the current evidence is insuffi- 
Fig. 1. Mathematical model framework

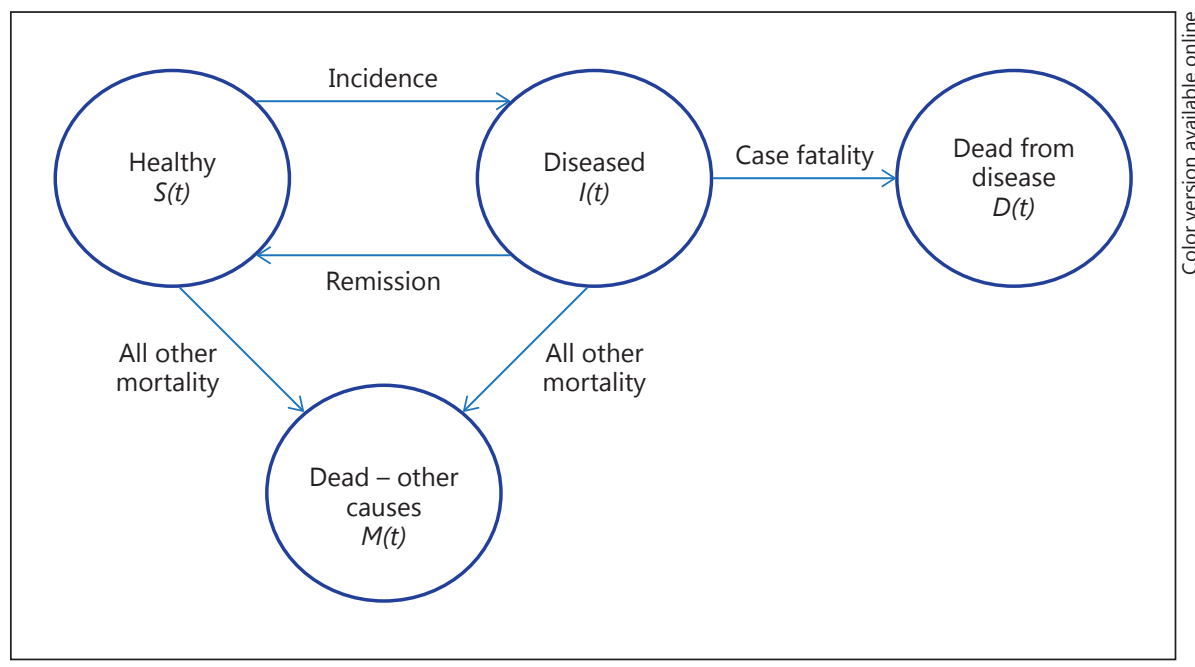

cient to assess the balance of harms and benefits of screening for AAA in women aged 65-75 years who have ever smoked, and it recommends against the routine screening for AAA in women who have never smoked [6].

Due to implementation of the Screening Abdominal Aortic Aneurysms Very Efficiently (SAAAVE) Act in January 2007, Medicare began covering the costs of a onetime ultrasound screening of men aged 65-75 years who ever smoked in their lifetime, or men and women who have a family history of AAA. However, this is a fairly narrow screening program, and it has been shown that the SAAAVE Act has had no discernable effect on AAA rupture or all-cause mortality [7].

AAA patients have a higher prevalence of cardiovascular risk factors compared with those without AAA, as well as an increased risk of death due to aneurysm rupture $[8,9]$. In a retrospective analysis of the National Inpatient Sample, the largest publicly available all-payer inpatient health care database in the USA, patients with ruptured AAA had a $39 \%$ in-hospital mortality rate [10]. Even among patients with successful repair of AAA, the average life expectancy is lower than in the general population [11].

According to the American Heart Association, in 2010 there were 16,417 any-mention deaths attributable to thoracic aortic aneurysm or AAA [12]. However, this number of aneurysm-related deaths may underestimate the true number of deaths due to the fact that patients with AAA ruptures outside of the hospital may not survive the trip to receive care [5]. According to a systematic review and meta-analysis, $32 \%$ of patients with AAA ruptures die before reaching the hospital [13].
Few data are available on the natural history of AAA and risk of death from other cardiovascular diseases attributable to AAA. Due to the relatively high prevalence of AAA among the elderly population, it is reasonable to assume that the true number of AAA-attributable deaths could be expected to be much higher than previously estimated.

\section{Methods}

This study used a disease-modeling software, DisMod II, developed by the World Health Organization for the Global Burden of Disease 2000 study. This has previously been used to model the burden of a wide range of other diseases, such as diabetes [14, 15], multiple sclerosis [16], schizophrenia [17], and malaria [18]. The mathematical model of DisMod II is a multistate life table describing a single disease, where transition hazards define the relationships between three states: healthy, diseased, and dead [19] (fig. 1). Those in the healthy state are defined as people being unaffected by the disease of interest. They are exposed to an incidence transition hazard, which may lead to them moving into the diseased state. From the diseased state they are exposed to a hazard of dying from the disease or a hazard of remission. The hazard of mortality from all other causes is the same for those in either the healthy or diseased state. A set of differential equations defines the relationships between the states and transition hazards, and allows for the calculation of the number of people in each state.

Input data for this study consisted of: age- and sex-specific population; age- and sex-specific all-cause mortality; size- and sexspecific AAA prevalence, and relative risk (RR) estimates of death for persons with AAA compared with persons without AAA, adjusted for age, ethnicity, height, weight, smoking, and cardiovascular disease history. AAA prevalence and RR estimates were segmented by size of aneurysm, where small AAA refers to aneurysms with an infrarenal diameter of $3.0-3.9 \mathrm{~cm}$ and large AAA refers to aneurysms with an infrarenal diameter of $\geq 4.0 \mathrm{~cm}$. 
Population data by sex and age were obtained from the United States Census Bureau's American FactFinder database [20]. Allcause mortality data by sex and age were obtained from the Centers for Disease Control and Prevention's National Vital Statistics System [21]. Estimates for prevalence came from results of the Department of Veterans Affairs Aneurysm Detection and Management (ADAM) study [4]. The ADAM study represents the largest AAA epidemiological study that involves the inclusion of women. A cubic spline interpolation curve was used to extend the prevalence estimates from 50-79 years to $\geq 50$ years. Measures of RR of death for those with AAA came from the Cardiovascular Health Study, a longitudinal cohort study from the UK [22]. Confidence intervals (CI) were calculated within DisMod II via a Monte Carlo simulation (parametric bootstrapping).

\section{Results}

The numbers of calculated prevalent cases and AAAattributable deaths based on the model are presented in tables 1 and 2, respectively. There were 2,347,339 total prevalent cases of AAA (95\% CI: 2,131,964-2,524,116) resulting in 41,371 AAA-attributable deaths (95\% CI: 34,090-49,234). Among males, there were $1,853,116$ prevalent cases (95\% CI: 1,686,511-1,995,377) and 22,680 AAA-attributable deaths (95\% CI: 18,472-28,922), representing $78.9 \%$ of the total prevalent cases and $54.8 \%$ of the total AAA-attributable deaths, respectively. Among females, there were 494,223 prevalent cases (95\% CI: 445,453-528,739) and 18,691 AAA-attributable deaths (95\% CI: $15,618-20,312)$, representing $21.1 \%$ of the total prevalent cases and $45.2 \%$ of the total AAA-attributable deaths, respectively. The 22,680 deaths among males accounted for $1.7 \%$ of male all-cause deaths in 2013, while the 18,691 deaths among females accounted for $1.5 \%$ of female all-cause deaths. Combined, AAAs were responsible for $1.6 \%$ of all-cause deaths in 2013.

Small AAAs accounted for $72.7 \%$ of the total prevalent cases and $59.1 \%$ of total AAA-attributable deaths. Among males, $68.7 \%$ of prevalent cases and $33.1 \%$ of AAA-attributable deaths were due to small AAAs. $87.9 \%$ of female prevalent cases and $90.8 \%$ of female AAA-attributable deaths were due to small AAAs. Large AAAs accounted for $27.3 \%$ of total prevalent cases and $40.9 \%$ of total AAAattributable deaths. Among males, large AAAs accounted for $31.3 \%$ of prevalent cases and $66.9 \%$ of AAA-attributable deaths, compared with $12.1 \%$ of prevalent cases and 9.2\% of AAA-attributable deaths among females.

Among those $\geq 55$ years of age, the AAA-attributable proportion of all-cause deaths increased to a peak between 75 and 84 years (fig. 2). For males in both age groups of 75-79 and 80-84 years, AAA-attributable
Table 1. Modeled prevalence of AAA, by sex and aneurysm size

\begin{tabular}{|c|c|c|c|c|}
\hline \multirow[t]{2}{*}{ Sex } & \multirow[t]{2}{*}{ Category } & \multirow{2}{*}{$\begin{array}{l}\text { Prevalent } \\
\text { cases, } \mathrm{n}\end{array}$} & \multicolumn{2}{|l|}{$95 \% \mathrm{CI}$} \\
\hline & & & lower & upper \\
\hline \multirow[t]{2}{*}{ Males } & $\begin{array}{l}\text { small AAA } \\
\text { large AAA }\end{array}$ & $\begin{array}{r}1,272,483 \\
580,633\end{array}$ & $\begin{array}{r}1,159,455 \\
527,056\end{array}$ & $\begin{array}{r}1,369,366 \\
626,011\end{array}$ \\
\hline & total & $1,853,116$ & $1,686,511$ & $1,995,377$ \\
\hline \multirow[t]{3}{*}{ Females } & small AAA & 434,321 & 391,349 & 465,068 \\
\hline & large AAA & 59,902 & 54,104 & 63,671 \\
\hline & total & 494,223 & 445,453 & 528,739 \\
\hline \multirow[t]{3}{*}{ Both } & small AAA & $1,706,804$ & $1,550,804$ & $1,834,434$ \\
\hline & large AAA & 640,535 & 581,160 & 689,682 \\
\hline & total & $2,347,339$ & $2,131,964$ & $2,524,116$ \\
\hline
\end{tabular}

Table 2. Modeled mortality attributable to AAA, by sex and aneurysm size

\begin{tabular}{|c|c|c|c|c|c|}
\hline \multirow[t]{2}{*}{ Sex } & \multirow[t]{2}{*}{ Category } & \multirow{2}{*}{$\begin{array}{l}\text { Deaths, } \\
\mathrm{n}\end{array}$} & \multicolumn{2}{|l|}{$95 \% \mathrm{CI}$} & \multirow{2}{*}{$\begin{array}{l}\text { Proportion } \\
\text { of all-cause } \\
\text { deaths, } \%\end{array}$} \\
\hline & & & lower & upper & \\
\hline \multirow[t]{3}{*}{ Males } & small AAA & 7,500 & 5,839 & 11,670 & 0.57 \\
\hline & large AAA & 15,180 & 12,633 & 17,252 & 1.16 \\
\hline & total & 22,680 & 18,472 & 28,922 & 1.74 \\
\hline \multirow[t]{3}{*}{ Females } & small AAA & 16,965 & 14,193 & 18,373 & 1.31 \\
\hline & large AAA & 1,726 & 1,425 & 1,939 & 0.13 \\
\hline & total & 18,691 & 15,618 & 20,312 & 1.45 \\
\hline \multirow[t]{3}{*}{ Both } & small AAA & 24,465 & 20,032 & 30,043 & 0.94 \\
\hline & large AAA & 16,906 & 14,058 & 19,191 & 0.65 \\
\hline & total & 41,371 & 34,090 & 49,234 & 1.59 \\
\hline
\end{tabular}

deaths accounted for 3.0\% of all-cause deaths, compared with $1.9 \%$ for females in both age groups of $75-79$ and 80-84 years.

\section{Discussion}

Modeling the burden of AAA using the DisMod II program resulted in over twice as many deaths attributable to AAA as current estimates by the American Heart Association. Interestingly, the results showed that females accounted for a disproportionately high percentage of total AAA-attributable deaths, $45.2 \%$, despite only accounting for $27.3 \%$ of the total prevalent cases.

AAA-attributable deaths due to large AAAs represented a more significant burden among males than fe- 
Fig. 2. Proportion of all-cause deaths attributable to AAA, by sex and selected age groups.

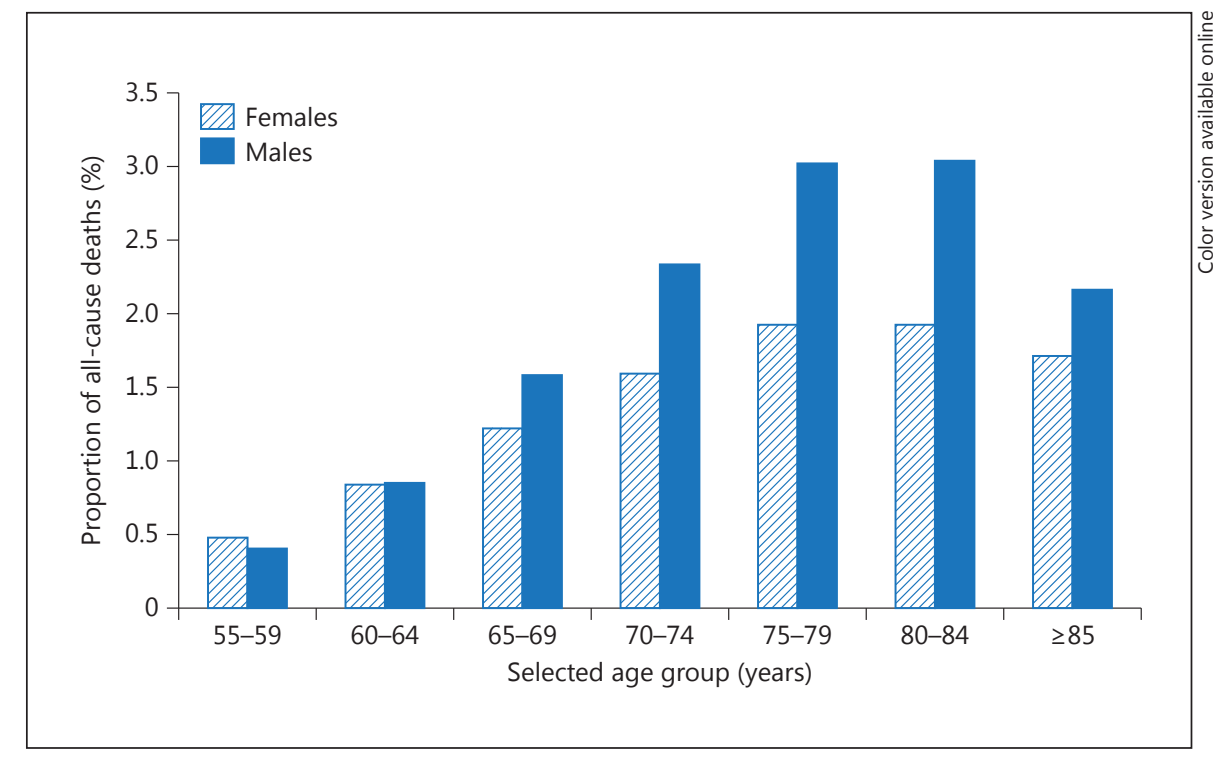

males: 66.9 versus $9.2 \%$, respectively. This is most likely due to the lower prevalence of large AAAs among women $(0.12 \%)$ compared with men (1.34\%) [4].

This study suggests that while AAA is less common among females than males, it is more likely to result in death. Among males, there were 81.7 prevalent cases of AAA per each AAA-attributable death, whereas among females this ratio is much lower at only 26.4 prevalent cases per death. These results are in line with other research stating that although females are generally protected from the development of AAAs, the ones that do develop behave more aggressively with higher growth and rupture rates [23].

Due to females having a disproportionately high percentage of total AAA-attributable deaths, as well as a lower ratio of prevalent cases to deaths compared with males, it is not unreasonable to suggest that perhaps current screening procedures for AAA should be expanded to include a more focused effort on identifying affected females.

The aim of this study was to provide more realistic estimates of the burden of AAA. However, there are some important limitations. The prevalence estimates include both diagnosed and undiagnosed patients, and cubic spline interpolation was used in order to apply these estimates to the entire population aged $\geq 50$ years rather than only 50-79 years as reported in the ADAM study. Also, due to a lack of available data, the RR of death input was taken from a study conducted in the UK and used in this model to estimate the disease burden in the USA. It is possible that there are underlying factors that would result in risk values differing between these countries, although according to the World Health Organization the UK and USA have comparable age-standardized mortality rates due to cardiovascular disease [24]. There are also elements of DisMod II that are subjective to the researcher, such as using various statistical means of smoothing input variables or using different weights for input variables. Using DisMod II is an interactive exercise, and the output results of the model may differ based on how the researcher utilizes different settings. Inconsistency of cross-sectional variables describing a disease may be real or deceptive, and there are inherent difficulties in combining measurements from different sources [25]. Despite these potential limitations, the results of this study demonstrate that the burden of deaths attributable to AAA may be considerably higher than current estimates suggest, particularly among females.

\section{Acknowledgments}

Financial support for this research was funded by Deerfield Management, a health care investment firm dedicated to advancing health care through investment, information, and philanthropy.

\section{Conflict of Interest}

The funder provided support in the form of a salary for the author, but did not have any additional role in the study design, data collection and analysis, decision to publish, or preparation of the manuscript. 


\section{References}

1 Palombo D, Lucertini G, Pane B, Mazzei R, Spinella G, Brasesco PC: District-based abdominal aortic aneurysm screening in population aged 65 years and older. J Cardiovasc Surg (Torino) 2010;51:777-782.

2 Aggarwal S, Qamar A, Sharma V, Sharma A: Abdominal aortic aneurysm: a comprehensive review. Exp Clin Cardiol 2011;16:11-15.

3 Lederle FA, Johnson GR, Wilson SE, Chute EP, Hye RJ, Makaroun MS, Bandyk D, Moneta GL, Makhoul RG; Aneurysm Detection and Management Veterans Affairs Cooperative Study: The aneurysm detection and management study screening program: validation cohort and final results. Arch Intern Med 2000;160:1425-1430.

4 Lederle FA, Johnson GR, Wilson SE; Aneurysm Detection and Management Veterans Affairs Cooperative Study: Abdominal aortic aneurysm in women. J Vasc Surg 2001;34: 122-126.

5 Lee ES, Pickett E, Hedayati N, Dawson DL, Pevec WC: Implementation of an aortic screening program in clinical practice: implications for the Screen for Abdominal Aortic Aneurysms Very Efficiently (SAAAVE) Act. J Vasc Surg 2009;49:1107-1111.

6 Final update summary: abdominal aortic aneurysm: screening. US Preventive Services Task Force. July 2015. http://www.uspreventiveservicestaskforce.org/Page/Document/ UpdateSummaryFinal/abdominal-aortic-aneurysm-screening (accessed December 1, 2015).

7 Shreibati JB, Baker LC, Hlatky MA, Mell MW: Impact of the Screening Abdominal Aortic Aneurysms Very Efficiently (SAAAVE) Act on abdominal ultrasonography use among Medicare beneficiaries. Arch Intern Med 2012;172:1456-1462.

8 Alcorn HG, Wolfson SK Jr, Sutton-Tyrrell K, Kuller LH, O'Leary D: Risk factors for abdominal aortic aneurysms in older adults enrolled in the Cardiovascular Health Study. Arterioscler Thromb Vasc Biol 1996;16:963-970.
9 Plumeekers HJ, Hoes AW, van der Does E, van Urk $\mathrm{H}$, Hofman A, de Jong PT, Grobbee DE: Aneurysms of the abdominal aorta in older adults. The Rotterdam Study. Am J Epidemiol 1995;142:1291-1299.

10 Dua A, Kuy S, Lee CJ, Upchurch GR Jr, Desai SS: Epidemiology of aortic aneurysm repair in the United States from 2000 to 2010. J Vasc Surg 2014;59:1512-1517.

11 Galland RB, Whiteley MS, Magee TR: The fate of patients undergoing surveillance of small abdominal aortic aneurysms. Eur J Vasc Endovasc Surg 1998;16:104-109.

12 Mozaffarian D, Benjamin EJ, Go AS, Arnett DK, Blaha MJ, Cushman M, de Ferranti S, Després JP, Fullerton HJ, Howard VJ, Huffman MD, Judd SE, Kissela BM, Lackland DT, Lichtman JH, Lisabeth LD, Liu S, Mackey RH, Matchar DB, McGuire DK, Mohler ER 3rd, Moy CS, Muntner P, Mussolino ME, Nasir K, Neumar RW, Nichol G, Palaniappan L, Pandey DK, Reeves MJ, Rodriguez CJ, Sorlie PD, Stein J, Towfighi A, Turan TN, Virani SS, Willey JZ, Woo D, Yeh RW, Turner MB; American Heart Association Statistics Committee and Stroke Statistics Subcommittee: Heart disease and stroke statistics - 2015 update: a report from the American Heart Association. Circulation 2015;131:e29-e322.

13 Reimerink JJ, van der Laan MJ, Balm R, Legemate DA: Systematic review and meta-analysis of population-based mortality from ruptured abdominal aortic aneurysm. Br J Surg 2013;100:1405-1413.

14 Roglic G, Unwin N, Bennett PH, Mathers C, Tuomilehto J, Nag S, Connolly V, King H: The burden of mortality attributable to diabetes: realistic estimates for the year 2000. Diabetes Care 2005;28:2130-2135.

15 Roglic G, Unwin N: Mortality attributable to diabetes: estimates for the year 2010. Diabetes Res Clin Pract 2010;87:15-19.
16 Chung SE, Cheong HK, Park JH, Kim HJ: Burden of disease of multiple sclerosis in Korea. Epidemiol Health 2012;34:e2012008.

17 Phanthunane P, Vos T, Whiteford H, Bertram M, Udomratn P: Schizophrenia in Thailand: prevalence and burden of disease. Popul Health Metr 2010;8:24.

18 Abdalla SI, Malik EM, Ali KM: The burden of malaria in Sudan: incidence, mortality and disability-adjusted life-years. Malar J 2007;6: 97.

19 Barendregt JJ, Van Oortmarssen GJ, Vos T, Murray CJ: A generic model for the assessment of disease epidemiology: the computational basis of DisMod II. Popul Health Metr 2003; $1: 4$

20 US Census Bureau: American FactFinder, annual estimates of the resident population by single year of age and sex for the United States: April 1, 2010, to July 1, 2013. http:// factfinder2.census.gov (accessed February 16, 2015)

21 CDC - National Center for Health Statistics - deaths: final data for 2013. http://www. cdc.gov/nchs/deaths.htm (accessed February $16,2015)$.

22 Newman AB, Arnold AM, Burke GL, O'Leary DH, Manolio TA: Cardiovascular disease and mortality in older adults with small abdominal aortic aneurysms detected by ultrasonography: the Cardiovascular Health Study. Ann Intern Med 2001;134:182-190.

23 Lo RC, Schermerhorn ML: Abdominal aortic aneurysms in women. J Vasc Surg 2016;63: 839-844.

24 Mendis S, Puska P, Norrving B (eds): Global Atlas on Cardiovascular Disease Prevention and Control. Geneva, World Health Organization, 2011

25 Kruijshaar ME, Barendregt JJ, Hoeymans N: The use of models in the estimation of disease epidemiology. Bull World Health Organ 2002;80:622-628. 